\title{
Para a história conceitual da discriminação da mulher
}

\author{
$\frac{\text { MARISA Lopes }}{\text { Professora do Departamento de Filosofia }}$
}

Resumo: A discriminação da mulher, longe de apresentar-se como um tema exclusivamente sociológico, encontra sua fundamentação conceitual na História da Filosofia, especialmente na filosofia de Aristóteles. Pretende-se mostrar aqui como o filósofo, a partir de seus pares conceituais metafísicos, potência/ato e matéria/forma, deriva a incompletude, a impotência, a mutilição e, por fim, a incapacidade ética e política da mulher.

Palavras-chave: Discriminação, Mulher, Aristóteles.

\begin{abstract}
Far from presenting itself as an exclusively sociological issue, women's discrimination has its conceptual ground in the history of philosophy, specially in Aristotle's philosophy. It is our aim here to show how the philosopher derives incompleteness, impotency, mutilation, and, finally, women's ethical and political incapacity from his metaphysical conceptual pairs potency/act, and matter/form.

Keywords: Discrimination, Woman, Aristote.
\end{abstract}

"Será justo, então, o réu Fernando Cortez, primário, trabalhador, sofrer pena enorme e ter a vida estragada por causa de um fato sem consequências, oriundo de uma falsa virgem? Afinal de contas, esta vítima, amorosa com outros rapazes, vai continuar a sê-lo. Com Cortez, assediou-o até se entregar. E o que em retribuição lhe fez Cortez? Uma cortesia...". ${ }^{1}$

1. Pimentel, S. "Quando gritar não é suficiente" (entrevista). In: O Estado de $S$. Paulo. Caderno Aliás, 30/08/2009, p. J4. 
É difícil acreditar que a vítima tenha se sentido honrada com semelhante cortesia. Nem ela nem as muitas mulheres que se tornam duplamente vítimas ao serem expostas a afrontosas decisões judiciais sobre crimes de estupro.

Silvia Pimentel, em conjunto com Valéria Pandjiarjian e Ana Lúcia Schritzmeyer, coletou e publicou, em 1997, um livro com 50 decisões de tribunais de Justiça de todo o Brasil com lamentável conteúdo. Apesar dos avanços obtidos com a Lei 12.015, de 07/08/2009, que suprimiu o atentado violento ao pudor e o incluiu no artigo que trata do estupro, qualificado, agora, como crime contra a dignidade sexual, as autoras mantêm a convicção de que "o crime de estupro era [por que não, é?] o único no mundo em que a vítima é acusada e considerada culpada da violência praticada contra ela". ${ }^{2}$

O recente caso Geyse, estudante da Uniban, confirma o diagnóstico: agindo por meio do terror, a turba pseudo-universitária brada contra a estudante palavras que soariam bem aos ouvidos dos velhos inquisidores.

O século XXI ainda não se desvencilhou de uma ratio masculinizante e estruturante de uma cosmologia e de uma antropologia

que assegura a forma feminina como imperfeição, seguindo-se a consequência violenta de sua minoridade político-social e sua constante qualidade de ente adoecido, histérico... Nada há, substancialmente, que separe a 'recta ratio' do fanatismo praticado por machos, responsáveis pela purificação mental e corpórea do gênero humano. ${ }^{3}$

Fanatismo capaz de produzir estultices como as que escreveu Moebius (1853-1907), médico e psiquiatra alemão. O livro de Moebius, Inferioridade da mulher: a deficiência mental fisiológica da mulher $^{4}$, que passo a expor, parte da constatação de que as fa-

2. Idem.

3. Romano, R. "A mulher e a desrazão ocidental". In: Folha de São Paulo, Folhetim, 03/04/1987, p. B-7.

4. Moebius, P. J. Inferioridad de la mujer (la deficiencia mental fisiológica de la mujer). Versão de A. Conca. Buenos Aires: Editorial Tor, s/d. 
culdades intelectuais do homem e da mulher são muito diferentes. Diferença que pode ser relativa e, neste caso, as mulheres teriam maior capacidade para uma coisa e os homens para outra, ou absoluta, as mulheres são em si mesmas deficientes em relação aos homens. A "sabedoria" proverbial - cabelos longos, cérebro curto - fornece a "verdade" dos tempos imemoriais. Contudo, o mais valioso para os médicos seria compreender claramente o estado intelectual da mulher e o valor de sua deficiência intelectual para que pusessem em ação todo o seu poder para combater, em favor da humanidade, as tendências contranaturais ${ }^{5}$ dos/das feministas.

Trata-se então de apresentar as "provas científicas" que fundamentam suas, no plural, deficiências. Em primeiro lugar, existe uma deficiência anatômica na mulher, um retardo, diz o autor, no desenvolvimento da circunvolução do lóbulo frontal e temporal, semelhante, aliás, à encontrada nos homens pouco desenvolvidos, como os negros.

A necessidade de cuidar dos filhos é a causa da diferença entre os sexos. A eterna sabedoria não pôs ao lado do homem outro homem provido de útero [tudo indica que o autor o lamente], mas outorgou à mulher tudo de que necessita para o melhor desempenho de seus nobilíssimos deveres, embora não the tenha outorgado a energia mental do homem. Se se quer que ela cumpra bem seus deveres maternais, é necessário que não possua um cérebro masculino, caso contrário veríamos atrofiarem os órgãos maternos. A mulher deve ser, antes de tudo, mãe amorosa e abnegada, como exige a natureza. Quando ela não cumpre seu dever em relação à espécie e quer viver sua vida intelectual ${ }^{6}$ está como que ferida por uma maldição, cujo castigo recairá também sobre os homens e sua posteridade. A energia e as aspirações por novos horizontes, a fantasia e a ânsia por conhecimentos novos serviriam apenas para fazer a mulher inquieta e transtornar seus deveres maternais. A mulher deve compreender que ela é assim por vontade da natureza e abster-se de rivalizar com o homem. Sirvam de exemplo as exal-

5. Meu destaque.

6. Destaque do autor. 
tadas modern-style, que parem mal e são péssimas mães. Ademais, quanto mais se propaga a civilização, menos se procria.

Do ponto de vista do comportamento, seu instinto a torna parecida com as bestas. Característico disso é a sua falta de opinião, a faculdade para saber diferenciar por si mesma o bem e o mal, no que depende, para isso, de uma influência extrínseca. As mulheres são rígidas conservadoras e odeiam a novidade, a não ser nos casos em que o novo lhes traga vantagem pessoal ou quando essa novidade agrada a um amante. A lei, portanto, deve considerar a deficiência mental fisiológica da mulher e não julgá-la como a um homem. A sua incapacidade para dominar as tempestades afetivas e a falta de sentido da equidade provam que é uma grande injustiça julgar ambos os sexos igualmente.

Sua moral é a moral do sentimento, ou seja, uma inconsciente retidão. Sua coragem deve servir para defender sua prole, pois exercer esse valor em outras ocasiões só a molesta. Justiça para elas é um conceito vazio de sentido.

Sem escrúpulos, pode-se afirmar que a natureza deu preferência ao homem e tem demonstrado querer formar dele um tipo mais perfeito pelo fato de fazê-lo se desenvolver mais tarde do que a mulher, predileção que é evidente na medida em que permite ao homem conservar as faculdades adquiridas até o fim de sua vida.

Com frequência, e com boas intenções, os homens que sugeriram às mulheres a mania da emancipação põem em prática o ardil de fazê-las crer que unicamente lhes faltou o exercício mental porque, como as negras da África, têm sido escravas do macho de músculos robustos. Sua ampla escravidão seria a causa de sua mente ter atrofiado. Aqueles que insistem, inclusive mais do que Moebius, segundo ele mesmo, na debilidade intelectual e moral do sexo feminino porque crêem que essa debilidade está relacionada a hábitos, portanto, modificáveis mediante a educação, igualmente crêem poder impor suas leis sobre a natureza - um erro, evidentemente.

Àqueles que o consideram um "obscurantista, cujo menor pecado é o da ignorância" , ele afirma que defende os interesses

7. Moebius, P. J. Inferioridad de la mujer (la deficiencia mental fisiológica de la mujer), p. 90. 
femininos contra seus adversários e luta contra o falso intelectualismo e o falso liberalismo que prega a conquista de uma nivelação estéril. Os verdadeiros adversários das mulheres são os feministas. A inferioridade do cérebro feminino é uma condição útil e indispensável.

Por isso,

[...] devemos esperar toda a saúde unicamente da sabedoria do homem, pelo menos até o ponto que a intervenção humana pode alcançar; isto é, que o homem deverá dizer clara e terminantemente à mulher que não quer saber nada de liberdade incondicional. $\mathrm{E}$ se o homem o faz seriamente, terminará de uma vez por todas o movimento feminista. ${ }^{8}$

Sabemos que, não tanto tempo depois, ideias como as de Moebius se tornaram dominantes na Alemanha nazista, aquela do triplo K: Kirche, Küche, Kinder.

Deficiente, inferior, incapaz, enferma: todos esses qualificativos associados à mulher não são o produto de um delírio individual, mas de uma ratio masculinizante ${ }^{9}$ estruturante de uma antropologia e de uma cultura que concebe a mulher como um ser inacabado e imperfeito, naturalmente inferior ao homem e incapaz para a vida social e política.

Ainda que tal concepção não tenha sido a única na história do pensamento ocidental, e a despeito de feministas como Eurípedes, Sócrates, Aristófanes, Platão e Xenofonte, serão as pseudo-teorias de Aristóteles sobre a natureza da mulher e do escravo que prevalecerão e fornecerão o referencial teórico para essa tendência misógina. ${ }^{10}$

Encontramos as explicações sobre a incapacidade da mulher da Metafísica à Politica. No livro inaugural da Metafísica, Aristóteles, ao revisar as teorias dos pensadores ou filósofos que o

8. Idem, p. 158.

9. Para usar os termos que Roberto Romano empresta de Brian Easlea.

10. Cf. Wright, F.A. Feminism in greek literature from Homer to Aristote. Londres: George Routledge \& Sons, 1923. 
precederam sobre as primeiras causas e princípios de tudo o que existe, isto é, as causas ou princípios pelos quais as coisas são e são cognoscíveis, lembra que alguns pitagóricos concebiam os contrários como os princípios dos seres e derivavam todos os fenômenos das seguintes oposições fundamentais:

$$
\begin{aligned}
\text { limite-ilimitado } & \text { repouso-movimento } \\
\text { ímpar-par } & \text { reto-curvo } \\
\text { um-múltiplo } & \text { luz-trevas } \\
\text { direito-esquerdo } & \text { bom-mau } \\
\text { macho-fêmea } & \text { quadrado-retângulo }
\end{aligned}
$$

O limitado é preferível ao ilimitado, pois se tudo fosse ilimitado não haveria conhecimento possível. $\mathrm{O}$ um (unidade) é o princípio de todas as coisas. O ser é luz, o não-ser, trevas. Os pares de opostos indicam um melhor e um pior: a mulher pertence ao que é enantion, adjetivo que indica a ideia de hostilidade, adversidade, antagonismo e, por extensão, oposição, contrariedade.

Pitágoras, neste aspecto, não inova. O mito das raças, narrado por Hesíodo no poema Os trabalhos e os dias, conta a sucessão de diversas raças de homens que viveram e morreram: a de ouro, de prata, de bronze e de ferro. Hesíodo acrescenta uma quinta, a dos heróis, que não tem correspondência metálica, intercalada entre a generação do bronze e a do ferro. A última raça, à qual o poeta pertence, e se lamenta por isso, representa um mundo ambíguo, definido pela coexistência de contrários. O bem tem como contrapartida o mal, o homem implica a mulher, o nascimento, a morte, a juventude, a velhice, a abundância, a escassez, a felicidade, a infelicidade. Segundo Vernant, a passagem de uma idade a outra não indicaria exatamente uma decadência progressiva, pois não há uma temporalidade linear e contínua, "mas fases que se alternam segundo relações de oposição e complementariedade. O tempo não se desenrola segundo uma sucessão cronológica, mas a partir de relações dialéticas de um sistema de antinomias". ${ }^{11}$ Contraposições e relações antinômicas que operam especialmente

11. Vernant, J. P. Mythe et pensée chez les Grecs. Etudes de psychologie historique. I. Paris: François Maspero, 1971, p. 21.

86 
na idade de ferro, idade sem pouca afinidade com as narrativas heróicas.

Prometeu é condenado a conviver com Pandora, responsável por todas as misérias dos homens de ferro: "para a raça de ferro, a terra e a mulher são ao mesmo tempo princípios de fecundidade e potências de destruição". ${ }^{12}$ Tal como as abelhas, que

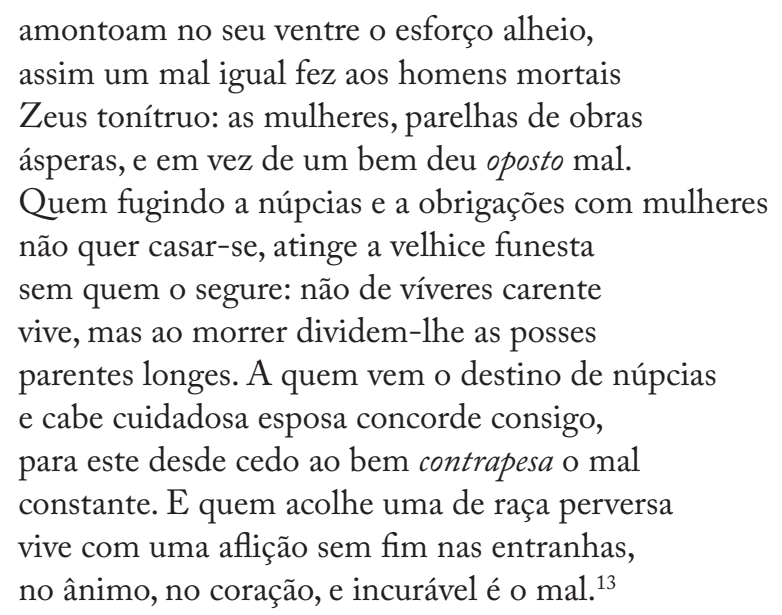

A figura feminima aparece como um castigo que, entre outros, Zeus inflige a Prometeu pelo roubo do fogo dos deuses. Desde então, o homem, condenado por sua hybris, sua desmesura, deve viver num mundo no qual reina a ambiguidade, a desordem, a injustiça, a miséria, o trabalho para viver. Com a passagem da idade do ouro, em que reinava a diké, a justiça, à idade de ferro, domínio da hybris sobre a diké, Hesíodo mostra, segundo Vernant, a arquitetura que preside a organização da sociedade humana e do mundo divino, segundo funções, valores e uma certa lógica que orienta essa arquitetura e regra o jogo de oposições interno a cada idade e entre elas: a tensão entre diké e bybris. ${ }^{14}$

12. Idem, p. 33.

13. Hesíodo. Teogonia. Estudo e trad. de JAA Torrano. São Paulo: Iluminuras, 1995, 3a ed., vv. 599-612. A ênfase é minha.

14. Vernant, op. cit., p. 34-8. 
Parece, portanto, que na própria formação do pensamento do homem ocidental e na modelagem das peças que compõem a "arquitetura do espírito"15 - os modos de expressão simbólica, tempo, espaço, causalidade, memória, imaginação, sensibilidade, organização da vontade, dos atos, da pessoa -, uma certa projeção no mundo como um todo de valores culturais tão arraigados que parecem "naturais", "objetivos", dirige e orienta a identificação entre o negativo e a fêmea, o positivo e o macho. Mesmo que, a crer em Aristóteles, a diferença entre macho e fêmea não seja essencial, mas acidental, assim como é acidental para a pessoa ser branca ou preta.

Ser fêmea ou ser macho é uma propriedade por si do gênero animal, mas isso não os faz diferirem, nem fêmea nem macho, seja pelo gênero seja pela espécie, que é ser animal racional. Cavalo e homem são espécies distintas do gênero animal, mas não mulher e homem; sua diferença antes concerne a uma modificação na matéria (elemento corpóreo), não na forma (essência). ${ }^{16}$

Contrariedades relativas à forma produzem espécies distintas, como os animais terrestres ou alados, ao passo que contrariedades relativas à matéria produzem diferença na coisa entendida como matéria, ou seja, no composto concreto. ${ }^{17}$ Sócrates, por exemplo, é um ser concreto composto de forma (essência) e matéria (carne, nervos, ossos, sangue). Ser branco para Sócrates é uma modificação na matéria que não produz nenhuma diferença em sua forma, sua essência. Do mesmo modo, "macho e fêmea são afecções (pathê) próprias do animal, e não se referem à substância, mas só à matéria e ao corpo. É por isso que do mesmo esperma, de acordo com a modificação (pathós) que venha a sofrer, deriva o macho ou a fêmea". ${ }^{18}$

O termo matéria (hylé), sabemos, nomeia uma das causas originárias das coisas. Ela é o material primeiro de que consiste ou

15. Idem, p. 6 .

16. Aristóteles. Metafísica, I, 9, 1058a 30-31. Doravante Met.

17. Met., X, 9, 1058b 1-10.

18. Met., X, 9, 1058b 21-23. Neste contexto, é lícito tomar o termo "substância" (ousía) como sinônimo de essência. 
é feito qualquer coisa natural ou artificial: por exemplo, a estátua provém do bronze, a taça, da prata, os corpos, do fogo, da terra, da água, do ar.

Por matéria deve-se compreender, no entanto, o que, em si mesmo, não é um ser particular, mas tem a potência para sê-lo ou, em outras palavras, aquilo que, embora não seja em ato um ser determinado, o é em potência: por exemplo, a madeira, que, não sendo algo determinado, tem a potência ou capacidade para ser uma mesa ou uma cadeira. ${ }^{19}$

Em função de sua natureza indeterminada, a matéria, segundo a Física, é não-ser: a madeira, embora ainda não o seja, pode ser algo determinado, por exemplo, esta mesa. $\mathrm{Na}$ medida em que pode vir-a-ser algo determinado, a matéria está perto do ser, tende para o ser e o deseja. A matéria deseja ou tende para a forma (ser), como uma fêmea tende para o macho e o feio para o bonito..$^{20} \mathrm{~A}$ forma, ao contrário, não deseja a si mesma porque nada lhe falta. ${ }^{21}$

A natureza deseja realizar plenamente e bem aquilo em que ela inere como princípio de movimento e repouso (geração e perecimento). Realizar plenamente significa atualizar, tanto quanto possível, a essência de um ser, a sua forma. Assim, a matéria, um não-ser, deseja ou tende para a forma porque, desse modo, tende para o seu bem, que é ser. A matéria, em certo sentido incompleta, é atraída pela forma, pela plenitude de ser; analogamente, a fêmea e o feio, por suas incompletudes, são atraídos pelo macho e pelo belo.

A matéria, como causa, é como a mãe: causa coeficiente do que é engendrado. É por isso que, afirma Aristóteles, quando se fala do universo, atribui-se à terra uma natureza feminina e o nome de mãe, e ao céu e ao sol, o nome de gerador e de pai.

É claro que a fonte de pesquisa de Aristóteles não é Hesíodo, no entanto, não deixa de ser curioso resgatar a ancestralidade da associação entre fêmea-generatriz e macho-gerador.

19. Met., VIII, 1, 1042a 26-28.

20. Enquanto atributos acidentais da matéria.

21. Aristóteles. Física, I, 9, 192a 19-25. Doravante Fis. 
Veio com a noite o grande Céu, ao redor da Terra desejando amor sobrepairou e estendeu-se a tudo. Da tocaia o filho [Cronos] alcançou com a mão esquerda, com a destra pegou a prodigiosa foice longa e dentada. $\mathrm{E}$ do pai o pênis ceifou com ímpeto e lançou-o a esmo para trás. Mas nada inerte escapou da mão: quantos salpicos respingaram sanguíneos a todos recebeu-os a Terra; com o girar do ano gerou as Erínias duras, os grandes Gigantes rútilos nas armas, com longas lanças nas mãos, e Ninfas chamadas Freixos sobre a terra infinita. ${ }^{22}$

A Terra e a fêmea recebem a semente, o sêmen, o princípio causador ${ }^{23}$, a partir do qual algo é gerado. Embora a fêmea figure como causa, ela é o elemento passivo, enquanto o macho é o elemento ativo, pois é dele que parte o princípio do movimento, o princípio da mudança, da mesma maneira que do artesão parte o princípio de movimento que produz uma mesa a partir da madeira. $\mathrm{E}$ assim como a madeira não engendra a mesa, a fêmea não engendra nada a partir de si mesma: é necessário um princípio que inicie o movimento e o determine. A natureza se serve do esperma como o artesão se serve do instrumento, isto é, ela se serve de algo que é causa da mudança ou da passagem de um estado a outro. Desse modo, tudo o que é gerado é gerado pela ação de algo em ato (forma) sobre algo que é potencialmente capaz de receber as determinações do que atualmente é: a madeira recebe, por meio do instrumento, a configuração da mesa que, por sua vez, já está presente em ato na alma do artesão.

O macho fornece a forma e o princípio do movimento, a fêmea, o corpo e a matéria. Em Metafísica, VIII, 4, 1044a 34 encontramos a mesma ideia: "Qual a causa material do homem? Não é o mênstruo? E qual a causa motora? Não é o esperma? E qual é a causa formal? A essência do homem. E qual a causa final? $\mathrm{O}$

22. Hesíodo, Teogonia, vv. 176-187. Ênfase minha.

23. Não surpreende que o sinônimo de semente, além de "esperma", seja "causa". 
fim (télos) do homem". O macho, enquanto macho, é o motor e o agente, causa do ser produzido; a fêmea, enquanto fêmea, paciente, portadora da matéria a partir da qual algo determinado vem à existência pela ação de um princípio ativo que é causa do ser produzido. Nesse sentido, o princípio masculino é portador da essência (ser humano), do gênero (animal) e das características individuais. ${ }^{24}$

A separação entre macho e fêmea representa a separação entre o melhor e o menos bom, e eles só se juntam para gerar, função comum dos dois. ${ }^{25}$ Nenhum animal é fêmea ou macho por todo o corpo, mas se distingue por sua função (uma potência e uma ação) e por órgãos apropriados para realizá-la. Desse modo, fêmea é o ser que engendra em si mesmo, macho é o ser que engendra em outro. Para realizar sua função, a fêmea é dotada de útero, o macho, de testículos e pênis. ${ }^{26}$

Do ponto de vista de sua fisiologia, o líquido seminal é um resíduo do alimento em seu último grau de elaboração, isto é, é o produto que vem do sangue por cocção, que, por sua vez, é o produto da cocção final do alimento. ${ }^{27}$ Por sua própria natureza, o líquido seminal (produto final da cocção do sangue) estaria presente em todas as partes do corpo, no entanto, por ser um resíduo como a urina ou as fezes, não permanece espalhado, mas "guardado" no útero, nas partes sexuais e na mama. ${ }^{28}$

A fêmea, no entanto, é impotente para operar a cocção do sangue transformando-o em esperma em função da frieza de sua natureza. Nela a cocção é menos intensa e disso resulta a produção de uma grande quantidade de líquido sanguinolento (o mênstruo), resíduo análogo ao líquido seminal. Aliás, é pela qualidade do sangue (sangue mais frio) que Aristóteles explica o fato de a fêmea ser mais frágil. O fluxo menstrual explica o fato de as fêmeas não

24. Aristóteles. Geração dos animais, IV, III, 767b 24 e ss. Doravante $G A$.

25. GA, II, I, 732a 4-7.

26. $G A, \mathrm{IV}, \mathrm{I}, 766 \mathrm{a} 2-5$.

27. $G A, \mathrm{I}, 18,726 \mathrm{a} 25-27$.

28. $G A, \mathrm{I}, 20,728 \mathrm{a} 21$ ss. 
terem frequentemente hemorróidas, não sangrar pelo nariz, terem a pele mais fina e mais lisa, serem inferiores fisicamente em relação aos machos e mais pálidas. ${ }^{29}$

Aristóteles contesta a opinião segundo a qual o esperma seria o produto da soma do resíduo do macho mais o da fêmea: o resíduo da fêmea é um análogo do líquido espermático, mas não é esperma, portanto não causa em sentido forte. Uma prova disso é que a fêmea em geral concebe sem ter tido prazer durante o coito. O prazer que acompanha a cópula é devido à emissão do esperma e à retenção da respiração, pela qual se acumula força. A fêmea contribui na geração fornecendo a matéria, o mênstruo, que serve de receptáculo ao esperma que, este sim, é princípio motor e que contém a forma. ${ }^{30}$

Para o filósofo a geração ocorre da seguinte maneira: o fluxo menstrual é esperma que, não sendo em estado puro, precisa ser elaborado. Há geração quando o mênstruo se mistura ao esperma. O que é em potência é produzido por algo que seja em ato, por isso é necessário que a forma seja em alguma coisa. ${ }^{31} \mathrm{O}$ esperma é resíduo animado de movimento idêntico ao existente no útero. Quando penetra o mênstruo, imprime movimento, movimento que a semente da fêmea já possui, porém em potência. A fêmea é como um macho mutilado ${ }^{32}$, pois o que lhe falta é o princípio da alma, que é trazido sempre pelo macho. As sementes são portadoras de alma, mas na fêmea esta alma está em potência (a alma nutritiva, responsável pelo crescimento), e é ativada pelo princípio motor externo: o esperma masculino ativa a alma. No esperma há o que torna as sementes fecundas, o calor, que não é o fogo, mas o pneuma (ar quente e água), cuja natureza é análoga ao elemento astral (éter) armazenado no esperma. A matéria do líquido seminal é o veículo do princípio psíquico (alma), sendo que o intelecto é a única porção que é independente da matéria. ${ }^{33}$

\footnotetext{
29. Idem, ibidem.

30. $G A, \mathrm{IV}, 1,765 \mathrm{~b} 11-15$.

31. $G A, \mathrm{II}, 1,733 \mathrm{~b} 23-30$.

32. $G A$, II, 3, 737a 27-28. Sem alma, e depois houve quem lembrasse de dizer que "sem pênis".

33. $G A, \mathrm{II}, 1,735 \mathrm{a} 5$ ss.
} 
O princípio material originário do qual é feito ou do qual deriva algo natural é privado de forma e incapaz de mudar em virtude unicamente da potência que lhe é própria. ${ }^{34}$ Por isso, quando o princípio (macho) não domina, quando é incapaz de operar a cocção por falta de calor e não impõe sua própria forma, é necessário que ele se transforme em seu contrário, pois a destruição de uma coisa é a transformação dela em seu contrário. Ora, o contrário do macho é a fêmea, e isso explica porque uns sejam macho, outros, fêmea. ${ }^{35}$

O desenvolvimento da fêmea, após o nascimento, é mais rápido que o do macho: ela chega mais rápido à puberdade, à idade madura, à velhice, mas isso se deve ao fato de as fêmeas serem por natureza mais fracas e mais frias, razão pela qual é preciso considerar sua natureza como uma imperfeição (anapería) natural. ${ }^{36}$

Todo esse aparato metafísico, físico e biológico conduz à descrença na capacidade natural da mulher para a virtude e para o comando.

$\mathrm{Na}$ Politica, Aristóteles afirma que "a relação entre homem e mulher consiste no fato de que, por natureza, um é superior, a outra, inferior, um governante, outra governada", consequentemente "a relação entre homem e mulher é de permanente desigualdade". ${ }^{37}$ Dada a desigualdade, a mulher e o escravo possuem a virtude que lhes convêm enquanto mulher e escravo, ou seja, a virtude que é apropriada ao cumprimento de suas funções como mulher e como escravo.

34. Ver também Fis., II, 1, 193a 9 ss.

35. $G A, \mathrm{IV}, 1,766$ a 18-21. O que se aproximaria do tratado hipocrático Do regime. Segundo Aristóteles, são duas razões para que nasçam fêmeas ao invés de machos: 1) necessidade natural para salvaguardar o gênero animal em que há distinção de sexos em vista da preservação da espécie; 2) quando o mênstruo não sofreu uma cocção suficiente a semente (o princípio motor) não se impõe, fazendo nascer uma fêmea (cf. $G A$, IV, III, 767b 15-23). Que se faça justiça: Aristóteles também admite que o macho, por sua própria incapacidade, consequência de sua juventude, velhice ou alguma outra causa aparentada, não se imponha à matéria no ato da geração (Idem, 767b 10-13).

36. $G A, \mathrm{IV}, 6,775$ a 11-16.

37. Aristóteles. Politica, I, 5, 1254b 12-13. Doravante Pol. 
A assimetria social acompanha a assimetria entre corpo e alma e à que concerne às faculdades da alma: a alma governa o corpo, a faculdade racional governa a faculdade apetitiva. Quem se deixa governar pelo corpo é degradado, pois obedece à parte irracional do composto corpo e alma. Quem não pode ou não usa a faculdade racional para escolher e decidir a respeito de suas ações e dirigir suas paixões está destinado a obedecer. Por isso o homem livre mandar no escravo, da mesma forma que o marido na mulher e o adulto na criança. Não se trata, como se vê, de negar racionalidade ao escravo, à mulher ou à criança, antes é a impossibilidade de orientar suas ações por um princípio interno de reflexão, deliberação e decisão que os tornam governados.

Declarar que o escravo não tem faculdade deliberativa (tò bouleutikón), que a mulher tem-na, mas carece da faculdade de decisão (tò ákyron) e que a criança - se for menino - tem a capacidade de decisão, mas ainda não desenvolvida (atelés $)^{38}$ não significa senão entender suas ações como heterônomas.

No vocabulário aristotélico a expressão "o que está em nosso poder" ou "o que depende de nós” (to eph’ hêmin) traduz a ação plenamente livre, isto é, a ação cujo princípio está em poder do agente iniciar ou não iniciar:

Com efeito, quando depende de nós (eph' hêmin) o agir, também depende de nós o não agir, quando depende de nós dizer não, também depende de nós dizer sim; por conseqüência, se depende de nós agir quando a ação é boa, também dependerá de nós não agir quando é ação é vil; e se não agir quando a abstenção é boa depende de nós, agir quando a ação é vil dependerá também de nós. Mas se depende de nós cumprir as ações boas e as ações vis, e paralelamente, de não as cumprir, e isso é ser, já dissemos, bons ou maus, resulta que está igualmente em nosso poder ser virtuoso ou vicioso. ${ }^{39}$

A passagem fornece uma condição bastante relevante acerca da responsabilidade moral do agente: as ações mediante as quais realizamos fins desejados são voluntárias, ou seja, está em nosso

38. Pol., I, 13, 1260a 12-14.

39. Aristóteles. Ética Nicomaquéia, III, 7, 1113b 7-15. 
poder realizá-las ou não, quando o homem, que é princípio de movimento, princípio de ação, detém o poder de agir ou de não agir quanto ao que é nobre ou vil, por isso está igualmente em seu poder tanto a virtude quanto o vício.

Ora, nem a mulher nem o escravo são entendidos como plenamente autores de suas ações, pois não podem deliberar ou decidir em toda e qualquer instância (pública e privada) acerca do que é bom para eles, seja do ponto de vista dos fins, seja do ponto de vista das próprias ações por intermédio das quais realizariam os fins que desejassem realizar.

Novamente a chaga social contamina a reflexão e a verdade. Aristóteles declara que seu apreço pela verdade é maior que sua amizade por Platão, razão pela qual é preciso criticar a Teoria das Ideias. No entanto, o que sobressai de opiniões, aliás, contrárias às de Platão sobre a mulher, tais como "a liberdade excessiva das mulheres é prejudicial ao fim da constituição e à felicidade da cidade", ou "os defeitos na condição das mulheres parecem não só causar uma certa falta de pudor na própria constituição [Esparta], como ainda contribuir para o amor ao dinheiro", ou ainda "[Esparta] foi negligente no que diz respeito às mulheres dado que estas vivem sem freio, entregues a toda a espécie de excessos e de indolência", ${ }^{40}$ não parece ir muito além de convicções que refletem uma certa visão cavernosa do mundo.

Mas em relação ao nosso tema, não foi Platão quem ganhou o jogo. É a Aristóteles que devemos muito da linguagem e do universo simbólico que codificaram a história da discriminação da mulher. Que, como se vê, longe de restringir-se a um tema sociológico, sempre permeou a História da Filosofia.

Se, como afirma Feuerbach, "Deus - tal como é, necessária e essencialmente -, é um objeto do homem, então na essência desse objeto exprime-se apenas a própria essência do homem", ${ }^{41}$ de igual modo, a figura feminina, o avatar-diabo de saia, decaído,

40. Pol., II, 9, 1269b 12 a 1270a 11.

41. Feuerbach, L. Princípios da Filosofia do Futuro. Lisboa: Edições 70, 1988, 7, p. 42. 
imperfeito, mutilado, não é menos a construção de um duplo que, por contraposição, ofereceu ao homem a possibilidade de elaborar uma certa identidade: aquela da qual Moebius e o advogado de Fernando Cortez, citado no início, tanto se orgulham.

\section{Bibliografia}

ARISTOTELES. Metafisica. Edición trilingüe [texto grego de Ross e latino de Moerbeke]. Traducción de V. García Yebra. Madrid: Gredos, 1970. 2 vols.

ARISTOTE. Physique. Texte établi et traduit par H. Carteron. Paris: Les Belles Lettres, 2 vols., 1926 e 1931.

De la Génération des animaux. Texte établi et traduit par P. Louis. Paris: Les Belles Lettres, 1961.

. The Nicomachean Ethic. With an English Translation by $\mathrm{H}$. Rackham. The Loeb Classical Library. London: Heinemann/ Cambridge: Harvard University Press, [1926] 1934.

ARISTÓTELES. Politica. Trad. e notas de A. C. Amaral e C. C. Gomes. Edição bilíngüe. Lisboa: Vega, 1998.

FEUERBACH, L. Princípios da Filosofia do Futuro. Lisboa: Edições 70, 1988.

HESÍODO. Teogonia. Estudo e trad. de JAA Torrano. São Paulo: Iluminuras, 3a ed.,1995.

MOEBIUS, P. J. Inferioridad de la mujer (la deficiencia mental fisiológica de la mujer). Versão de A. Conca. Buenos Aires: Editorial Tor, s/d.

PIMENTEL, S. "Quando gritar não é suficiente" (entrevista). In: $O$ Estado de São Paulo. Caderno Aliás, 30/08/2009.

ROMANO, R. "A mulher e a desrazão ocidental”. In: Folba de São Paulo, Folhetim, 03/04/1987.

VERNANT, J. P. Mythe et pensée chez les Grecs. Etudes de psychologie historique. I. Paris: François Maspero, 1971.

WRIGHT, F. A. Feminism in greek literature from Homer to Aristote. Londres: George Routledge \& Sons, 1923. 